EXTENDED REPORT

\title{
Increased plasma endothelin-1 levels in patients with progressive open angle glaucoma
}

\author{
M Emre, S Orgül, T Haufschild, S G Shaw, J Flammer
}

Br J Ophthalmol 2005;89:60-63. doi: 10.1136/bjo.2004.046755

$\begin{aligned} & \text { See end of article for } \\ & \text { authors' affiliations } \\ & \ldots \ldots \ldots \ldots \ldots \ldots . . . . . . .\end{aligned}$
Correspondence to:
Professor S Orgül,
University Eye Clinic Basel,
Mittlere Strasse 91, PO
Box, 4012 Basel,
Switzerland; sorgul@
magnet.ch
Accepted for publication
10 May 2004

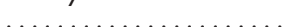

\begin{abstract}
Aim: To compare the plasma levels of endothelin-1 (ET-1) between patients with primary open angle glaucoma with visual field progression despite normal or normalised intraocular pressure and patients with stabile visual fields in a retrospective study.

Methods: The progressive group consisted of 16 primary open angle glaucoma patients and the group with stable visual field consisted of 15 patients. After a 30 minute rest in a supine position, venous blood was obtained for ET-1 dosing. Difference in the plasma level of ET-1 between two groups was compared by means of analysis of covariance (ANCOVA), including age, sex, and mean arterial blood pressure as covariates.

Results: ET-1 plasma levels were found to be significantly increased in patients with deteriorating ( 3.47 (SD 0.75$) \mathrm{pg} / \mathrm{ml}$ ) glaucoma when compared to those with stable $(2.59$ (SD 0.54$) \mathrm{pg} / \mathrm{ml}$ ) visual fields $(p=0.0007)$.

Conclusions: Glaucoma patients with visual field progression in spite of normal or normalised intraocular pressure have been found to have increased plasma endothelin-1 levels. It remains to be determined if this is a secondary phenomenon or whether it may have a role in the progression of glaucomatous damage.
\end{abstract}

$\mathrm{E}$ ndothelin-1 (ET-1) has been suggested to be a potential contributor to the pathogenesis of glaucoma. ${ }^{1}$ ET- 1 is one of the most potent vasoconstrictors and was first described by Yanagisawa and colleagues in 1988. ${ }^{2}$ Although ET-1 appears to act mainly as a local paracrine/autocrine peptide, circulating levels of endothelin seem also to have a biological significance, especially in pathological states of increased serum concentration. ${ }^{34}$

Increased plasma ET-1 levels have been described in normal tension glaucoma patients, ${ }^{56}$ although this was not confirmed in all studies with normal tension glaucoma patients ${ }^{7}$ or in studies with high tension glaucoma patients. ${ }^{89}$ The fact that aqueous ET-1 concentration is increased in primary open angle glaucoma ${ }^{8}{ }^{10}$ and in animal models of glaucoma ${ }^{11}$ underscores the possible contribution of endothelin to the pathogenesis of primary open angle glaucoma. Furthermore, chronic administration of ET-1 has been shown to produce an optic neuropathy similar to glaucoma. ${ }^{12-14}$

Because an active role of ET-1 in POAG would suppose a higher level in patients with active disease, we compared the plasma levels of ET-1 in POAG patients with progressive visual field deterioration to POAG patients with a stable damage.

\section{PATIENTS AND METHODS}

This study adhered to the tenets of the Declaration of Helsinki and was approved by the local ethics committee. Informed consent for the use of their clinical data in a scientific publication was obtained from each patient. Thirty one primary open angle glaucoma patients (seven men and 24 women), including normal tension glaucoma patients, were selected. Patients with closed iridocorneal angles, evidence of secondary glaucoma, pseudoexfoliation, pigmentary dispersion, a history of intraocular surgery (except for filtration surgery), any form of retinal or neuroophthalmologic disease that could result in visual field defects, or with a history of chronic systemic medication or disease, especially diabetes mellitus, systemic hypertension, occlusive vascular disorders, chronic heart failure, renal failure, glomerulonephritis, and autoimmune diseases, were not included.
Eyes had to have a visual acuity of $20 / 30$ or better and no clinical evidence of opacity of the media (nuclear sclerotic cataract, or the development of any degree of posterior subcapsular cataract) at the time the patient was included into the study. No attempt was done to wash out antiglaucoma medication. However, in order to control for the influence of medical or surgical glaucoma therapy, only patients using the same topical antiglaucoma medication in both eyes and throughout the entire follow up period for which stability or progression in visual field damage was evaluated, or patients subjected to filtration surgery prior to this observation period were included.

In each patient a diurnal intraocular pressure (IOP) curve (before arising from bed at $6.00 \mathrm{am}, 8.00 \mathrm{am}, 11.00 \mathrm{am}, 4.00$ $\mathrm{pm}$, and $10.00 \mathrm{pm}$ ) was obtained in both eyes the day ET-1 was given. Only patients showing no readings above $21 \mathrm{~mm} \mathrm{Hg}$ were considered for the present analysis.

All patients had typical glaucomatous disc and visual field damage. Only data from patients experienced in visual field testing were considered. After excluding the first fields from the series available, retrospective information for at least five consecutive visual field examinations had to be available in each patient for evaluation of progression. No alteration in treatment during this period was tolerated. The patients had $3 \mathrm{~mm}$ or larger pupil diameters when their fields were plotted and fields with poor reliability (fixation loss exceeding 20\% and false-positive or false-negative errors exceeding 33\%) were not considered.

Visual field examinations had been performed with the program $\mathrm{Gl}^{15}$ on the Octopus Visual Field Analyzer (Interzeag, Schlieren, Switzerland). The criteria for glaucomatous visual field defects were a cluster of three points (except rim points) in at least one hemifield reduced by $5 \mathrm{~dB}$ or greater, and including at least one point reduced by $10 \mathrm{~dB}$ or greater; a cluster of two points reduced by $10 \mathrm{~dB}$ or

Abbreviations: ET-1, endothelin-1; DBP, diastolic blood pressure; IOP, intraocular pressure; $M B P$, mean blood pressure; $S B P$, systolic blood pressure 
greater; or three adjacent points on the nasal horizontal meridian that differed by $5 \mathrm{~dB}$ or greater from their mirror points on the opposite side of the meridian.

The definition of visual field progression consisted of deepening of an existing scotoma, expansion of an existing scotoma, or a fresh scotoma in a previously normal part of the visual field, in the three last fields of the selected series per eye. A deepening or expansion of an existing scotoma was diagnosed if two adjacent points had declined $10 \mathrm{~dB}$ from their original values, and a new scotoma was diagnosed if an alteration meeting the criteria for a visual field defect occurred in a previously normal part of the field. In patients with only one eye showing progressive damage, this eye was selected for further evaluation; when both eyes showed progression, or no progression had occurred in both eyes, one randomly chosen eye was considered for further evaluation.

ET-1 plasma levels were determined by a specific radioimmunoassay, as described by d'Uscio et al. ${ }^{16}$ Venous EDTA blood samples $(20 \mathrm{ml})$ were taken after 30 minutes of rest in a supine position at room temperature at about $8.00 \mathrm{am}$. The blood samples were stored immediately on ice and cool centrifugation at $4^{\circ} \mathrm{C}$ was performed for 10 minutes. Plasma was separated at $4^{\circ} \mathrm{C}$ and kept at $-80^{\circ} \mathrm{C}$ until assay. Extraction was performed by absorption on $500 \mathrm{mg}$ SepPak Vac C18 cartridges (Millipore Ltd, Watford, UK). Columns were preactivated by successive washes with $5 \mathrm{ml}$ of $86 \%$ ethanol in $4 \%$ acetic acid, $5 \mathrm{ml}$ of methanol, $5 \mathrm{ml}$ of sterile distilled water, and $5 \mathrm{ml}$ of $4 \%$ acetic acid. A $2 \mathrm{ml}$ plasma sample acidified with $6 \mathrm{ml}$ of $4 \%$ acetic acid was then applied on the column with the flow rate of $3 \mathrm{ml} / \mathrm{min}$. The columns were then washed with $18 \mathrm{ml}$ of sterile distilled water, $1.8 \mathrm{ml}$ ethyl acetate, and $18 \mathrm{ml}$ of $24 \%$ ethanol in $4 \%$ acetic acid before ET was eluted with $86 \%$ ethanol in $4 \%$ acetic acid. The eluate was dried under nitrogen at $37^{\circ} \mathrm{C}$ and redissolved in $230 \mu \mathrm{l}$ of assay buffer composed of $0.1 \%$ phosphate buffer (pH 7.4), $0.05 \mathrm{~mol} / \mathrm{l} \mathrm{NaCl}, 0.1 \%$ Triton X-100, 0.02\% sodium azide, and $0.1 \%$ BSA. The radioimmunoassay of plasma ET was performed using synthetic human/porcine ET-1 (Sigma Chemical Co, St Louis, MO, USA), a rabbit antibody against synthetic ET (Peninsula Laboratories, San Carlos, CA, USA), and ${ }^{125}$ I-ET-1 (Amersham, Freiburg, Germany). The antibody has $100 \%$ cross reactivity with ET-1, 7\% with ET-2 and ET-3, $17 \%$ with big endothelin- 1 , and no cross reactivity with other peptides. The anti-ET antibody was reconstituted according to the manufacturer's instructions and then further diluted 1:3.5 with the assay buffer before adding $100 \mu \mathrm{l}$ to the standards or the reconstituted plasma samples $(100 \mu \mathrm{l})$ analysed in duplicate. After 24 hours of incubation, $100 \mu \mathrm{l}$ of ${ }^{125}$ I-ET-1 ( 10 to $12 \times 10^{3} \mathrm{cpm}$ per tube) was added, and incubation was allowed to continue for an additional 24 hours. The separation of bound and free antigen was performed with a second antibody method, and pellets were counted by a gamma counter (Canberra Packard). Reference values (mean (standard deviation)) in our laboratory are 1.42 (SD 0.28) $\mathrm{pg} / \mathrm{ml}$ for females and 1.67 (SD 0.34) $\mathrm{pg} / \mathrm{ml}$ for males.

Systemic blood pressure was recorded three times at three minute intervals by an automatic device (Profilomat; Disetronic, Burgdorf, Switzerland) after 30 minutes of rest in a supine position and after blood sampling at the opposite arm. This device measures the blood pressure automatically, using the same principle as the conventional mercury sphygmomanometer, with a cuff and a microphone. The average of the three consecutive blood pressure readings for systolic blood pressure (SBP) and diastolic blood pressure (DBP) were used to calculate the mean arterial blood pressure $(\mathrm{MBP})$ according to the formula: $\mathrm{MBP}=2 / 3 \times \mathrm{DBP}+1 / 3 \times$ SBP.
Data are given as mean (standard deviation). Differences between groups regarding age, systemic blood pressure, IOP, follow up period, and the number of visual fields obtained during the follow up period were assessed by means of Student's $t$ test for independent samples. Fisher's exact test was used to compare the distribution of female and male patients. Difference in the plasma level of ET-l between two groups was compared by means of analysis of covariance (ANCOVA) using age, sex, and mean arterial blood pressure as covariates. A p value below 0.05 was considered statistically significant.

\section{RESULTS}

Three male and 13 female patients satisfying criteria for progressive visual field damage and four male and 11 female patients with stable visual fields $(p=0.46)$ were recruited. Mean (SD) age was respectively 66.9 (SD 11.1) and 63.2 (14.5) years $(\mathrm{p}=0.43)$. There were no significant differences between groups with respect to age, SBP, DBP, MBP, IOP follow up period, and number of visual fields obtained during the follow up period (table 1). Furthermore, as shown in table 1, the visual field index "mean defect" (mean (SD)) at baseline for patients with progressive damage and stable visual fields was comparable, but had changed significantly in patients with progressive damage. Treatment of the patients is summarised in table 2. Three patients in each experimental group had filtration surgery prior to the observation period.

Plasma levels of ET-1 at the end of the observation period (see figure 1) were significantly higher in patients with progressive damage $(3.47(0.75) \mathrm{pg} / \mathrm{ml}$; range $2.34-5.17 \mathrm{pg} /$ $\mathrm{ml}$ ) compared with those with stable $(2.60$ (SD 0.54) pg/ml; range $1.91-3.45 \mathrm{pg} / \mathrm{ml}$ ) visual fields (ANOVA: $\mathrm{F}(1,29)=$ $13.94281 ; p=0.0008)$. This difference was still significant after controlling for the interaction of sex and including age and MBP as covariates into the model (ANCOVA: F $(1,25)=14.95 ; p=0.0007)$. Sex had a borderline significant effect (ANCOVA: $F(1,25)=4.25 ; p=0.0497)$, but the interaction between sex and disease progression was not significant (ANCOVA: F $(1,25)=1.84 ; \mathrm{p}=0.19)$.

\section{DISCUSSION}

The present study suggests an increased plasma level of ET-1 in primary open angle glaucoma patients with progressive damage when compared with primary open angle glaucoma patients with stable visual fields. This difference was independent of sex, age, and mean blood pressure. Furthermore, the values obtained among patients with a stable visual field were above the reference values established in our laboratory. A possible explanation for these findings could be that ET-1 may contribute primarily to the damaging process in glaucoma, but also remain increased secondarily to the

Table 1 Clinical parameters of the experimental groups (mean (SD)

\begin{tabular}{|c|c|c|c|}
\hline Parameter & Progressive group & Stable group & p Value \\
\hline $\mathrm{SBP}(\mathrm{mm} \mathrm{Hg})$ & 121.9 (18.9) & $114.8(12.3)$ & 0.23 \\
\hline $\mathrm{DBP}(\mathrm{mm} \mathrm{Hg})$ & $75.6(14.0)$ & $71.9(8.0)$ & 0.38 \\
\hline $\mathrm{MBP}(\mathrm{mm} \mathrm{Hg})$ & $91.0(15.0)$ & $86.2(6.4)$ & 0.26 \\
\hline Follow up (months) & $48.4(16.8)$ & $50.2(21.6)$ & 0.80 \\
\hline IOP at baseline $(\mathrm{mm} \mathrm{Hg})$ & $17.0(4.3)$ & $16.7(4.8)$ & 0.84 \\
\hline MD at baseline (dB) & $6.4(4.6)$ & $5.0(2.6)$ & 0.30 \\
\hline $\begin{array}{l}M D \text { at the end of } \\
\text { follow up }(\mathrm{dB})\end{array}$ & $12.0(5.2)$ & $4.8(3.3)$ & $<0.0001$ \\
\hline Number of visual fields & $6.6(1.6)$ & $7.4(2.9)$ & 0.36 \\
\hline
\end{tabular}

SBP, systolic blood pressure; DBP, diastolic blood pressure; MBP, mean arterial blood pressure; IOP, intraocular pressure; $M D$, visual field index "mean defect". 
Table 2 Topical glaucoma treatment

\begin{tabular}{lll}
\hline Drug & Progressive group & Stabile group \\
\hline Timolol & 1 & 0 \\
Betaxolol & 2 & 2 \\
Dorzolamide & 1 & 2 \\
Latanaprost & 4 & 0 \\
Brinzolamide & 0 & 1 \\
Dorzolamide + Timolol & 1 & 3 \\
Dorzolamide + Latanoprost & 1 & 2 \\
Dorzolamide + Brimonidin & 0 & 1 \\
Timolol + Latanoprost & 1 & 0 \\
Timolol + Pilocarpine & 1 & 0 \\
Betaxolol + Brinzolamide & 1 & 0 \\
\hline
\end{tabular}

damage. An alternative explanation would be that some patients in the group with stable visual fields were in an active stage of their disease, but did not yet satisfy the criteria used to define progression in visual field damage.

The cause for the increased levels of circulating ET-1 in primary open angle glaucoma patients is not clear. One may be tempted to explain the link between systemic levels of endothelin and glaucoma with the association of glaucoma and the primary vasospastic syndrome. ${ }^{17}$ High plasma levels of ET-l have been described in diseases associated with vascular dysregulation such as cerebral vasospasm after subarachnoid haemorrhages, ${ }^{18}{ }^{19}$ Raynaud's phenomenon, ${ }^{20}{ }^{21}$ and ischaemic heart disease. ${ }^{22}{ }^{23}$ Furthermore, it is believed that in some patients such as in individuals with drug induced coronary spasm, an abnormal response of the vascular endothelium to certain stimuli can lead to abnormally high levels of ET-1 and consequent vasoconstriction. ${ }^{23}$ An abnormal endothelial function with an abnormal release of ET-1 after a vasospastic stimulus has been suggested to be related to the genesis of vasospasm in glaucoma. ${ }^{24}$ Kaiser et al also demonstrated a faulty regulatory mechanism in the production of ET-1 in normal tension glaucoma: the physiologic increase in plasma ET-1 levels observed when subjects moved from a supine to an upright position was absent in the patients with normal tension glaucoma. ${ }^{7}$ Finally, the vascular response to ET-1 has been shown to be enhanced in subcutaneous resistance arteries from patients with $\mathrm{NTG}^{25}$ and glaucoma patients with lower blood pressure values react more sensitively to ET- $1 .{ }^{26}$

As a result of vascular events, ET may in turn have further vascular effects, including $\mathrm{ET}_{\mathrm{A}}$ mediated rapid vasoconstriction and $\mathrm{ET}_{\mathrm{B}}$ induced vasodilation mediated by nitric oxide and possibly TNF- $\alpha,{ }^{27}{ }^{28}$ but increased ET- 1 levels may also exert direct receptor mediated effects on retinal ganglion cells and resident glial cells. Retinal ganglion cell loss in glaucomatous optic neuropathy is associated with a disruption in anterograde axonal transport. ${ }^{29}{ }^{30}$ Theoretically, this can result either from nerve compression ${ }^{31}$ or from ischaemia. ${ }^{32}$ However, the effect of direct compression or ischaemia on axonal transport has been suggested to involve the loss of linear microtubule arrays in exposed axons, ${ }^{33}{ }^{34}$ whereas in glaucoma a rather selective dysregulation of axonal transport seems to occur. ${ }^{30}$ It has been hypothesised that mechanisms contributing to the perturbation of anterograde axonal transport could involve ET- $1 .{ }^{35}$ Indeed, intravitreal ET-1 induces a significant impairment of anterograde axonal transport in retinal ganglion cells, ${ }^{35}$ but, interestingly, $\mathrm{ET}_{\mathrm{A}}$ receptor mediated vasoconstriction seems not be a prerequisite for the effect of ET on axonal transport, and evidence has been shown that the observed perturbation might result from the stimulation of $\mathrm{ET}_{\mathrm{B}}$ receptors. Both receptor types $\mathrm{ET}_{\mathrm{A}}$ and $\mathrm{ET}_{\mathrm{B}}$ are expressed in retinal ganglion cells. ${ }^{36}$

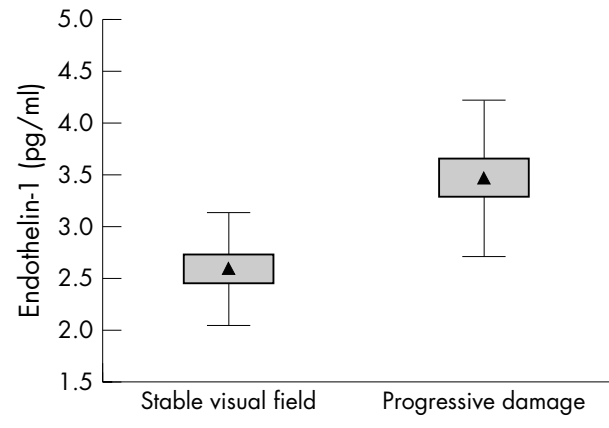

Figure 1 Plasma concentration of ET-1 in patients with glaucoma with and without visual field progression (triangle = mean; box = standard error of the mean; whiskers = standard deviation).

Alternatively, circulating levels of ET-1 may be linked indirectly to the loss of retinal ganglion cells in glaucoma. It has been shown that, through activation of both $\mathrm{ET}_{\mathrm{A}}$ and $\mathrm{ET}_{\mathrm{B}}$ receptors, ET- 1 can induce astroglial proliferation in cultured human optic nerve head astrocytes. ${ }^{37}$ It is, therefore, possible that increased ET-1 levels in glaucoma play a role in the astrocyte proliferation that occurs in glaucomatous optic neuropathy. ${ }^{38}$ Indeed, astrogliosis occurs not only in human glaucomatous optic nerve neuropathy, ${ }^{38}$ but also in animals with experimentally increased intraocular pressure. ${ }^{39}{ }^{40}$ Hypol thetically, normal interaction between glia and neurons may be disturbed during astrocytogliosis, which may enhance the rate of neuronal loss during glaucomatous damage.

The present study cannot conclusively prove the direct implication of ET-1 in the pathogenic process of glaucomatous optic neuropathy. This would require a prospective study with repeated dosing of plasma levels of ET-1 and, ideally, the assessment of the effect of endothelin receptor blockers.

\section{Authors' affiliations}

M Emre, S Orgül, T Haufschild, J Flammer, University Eye Clinic, Basel, Switzerland

S G Shaw, Department of Clinical Research, University of Berne, Berne, Switzerland

\section{REFERENCES}

1 Yorio T, Krishnamoorthy R, Prasanna G. Endothelin: is it a contributor to glaucoma pathophysiology? J Glaucoma 2002;11:259-70.

2 Yanagisawa $M$, Kurihara $\mathrm{H}$, Kimura $\mathrm{S}$, et al. A novel potent vasoconstrictor peptide produced by vascular endothelial cells. Nature 1988;332:411-15.

3 Inove A, Yanagisawa M, Kimura S, et al. The human endothelin family: three structurally and pharmacologically distinct isopeptides predicted by three separate genes. Proc Natl Acad Sci U S A 1989;86:2863-7.

4 Sakurai T, Yanagisawa M, Masaki T. Molecular characterization of endothelin receptors. Trends Pharmacol Sci 1992;13:103-8.

5 Sugiyama T, Moriya S, Oku H, et al. Association of endothelin-1 with normal tension glaucoma: clinical and fundamental studies. Surv Ophthalmol 1995;39(Suppl 1):S49-S56.

6 Cellini M, Possati GL, Profazio V, et al. Color Doppler imaging and plasma levels of endothelin-1 in low-tension glaucoma. Acta Ophthalmol Scand Suppl 1997:11-13.

7 Kaiser HJ, Flammer J, Wenk M, et al. Endothelin-1 plasma levels in normaltension glaucoma: abnormal response to postural changes. Graefe's Arch Clin Exp Ophthalmol 1995;233:484-8.

8 Tezel G, Kass MA, Kolker AE, et al. Plasma and aqueous humor endothelin levels in primary open-angle glaucoma. J Glaucoma 1997;6:83-9.

9 Hollo G, Lakatos P, Farkas K. Cold pressor test and plasma endothelin-1 concentration in primary open-angle and capsular glaucoma. J Glaucoma 1998;7:105-10.

10 Noske W, Hensen J, Wiederholt M. Endothelin-like immunoreactivity in aqueous humor of patients with primary open-angle glaucoma and cataract. Graefes Arch Clin Exp Ophthalmol 1997;235:551-2.

11 Kallberg ME, Brooks DE, Garcia-Sanchez GA, et al. Endothelin 1 levels in the aqueous humor of dogs with glaucoma. J Glaucoma 2002;1 1:105-9.

12 Orgul S, Cioffi GA, Wilson DJ, et al. An endothelin-1 induced model of optic nerve ischemia in the rabbit. Invest Ophthalmol Vis Sci 1996;37:1860-9.

13 Oku H, Sugiyama T, Kojima S, et al. Experimental optic cup enlargement caused by endothelin-1-induced chronic optic nerve head ischemia. Surv Ophthalmol 1999;44(Suppl 1):S74-S84. 
14 Chauhan BC, LeVatte TL, Jollimore CA, et al. Model of endothelin-1-induced chronic optic neuropathy in rat. Invest Ophthalmol Vis Sci 2004;45:144-52. 15 Flammer J, Jenni A, Bebie $H$, et al. The Octopus glaucoma $G 1$ program. Glaucoma 1987:9:67-72

16 d'Uscio LV, Barton M, Shaw S, et al. Structure and function of small arteries in salt-induced hypertension: effects of chronic endothelin-subtype-A-receptor blockade. Hypertension 1997;30:905-11.

17 Flammer J, Gasser P, Prunte C, et al. In: Drance SM, Van Buskirk EM, Neufeld AH, eds. Pharmacology of glaucoma. Baltimore: Williams \& Wilkins, 1992:273-83.

18 Zimmermann M. Endothelin in cerebral vasospasm. Clinical and experimental results. J Neurosurg Sci 1997;41:139-51.

19 Suzuki R, Masaoka H, Hirata Y, et al. The role of endothelin-1 in the origin of cerebral vasospasm in patients with aneurysmal subarachnoid hemorrhage. J Neurosurg 1992;77:96-100.

20 Zamora MR, O'Brien RF, Rutherford RB, et al. Serum endothelin-1 concentrations and cold provocation in primary Raynaud's phenomenon. Lancet 1990;336:1144-7.

21 Mangiafico RA, Malatino LS, Santonocito M, et al. Plasma endothelin-1 concentrations during cold exposure in essential acrocyanosis. Angiology 1996;47:1033-8.

22 Wenzel RR, Duthiers N, Noll G, et al. Endothelin and calcium antagonists in the skin microcirculation of patients with coronary artery disease. Circulation 1996:94:316-22.

23 Toyo-oka T, Aizawa T, Suzuki N, et al. Increased plasma level of endothelin-1 and coronary spasm induction in patients with vasospastic angina pectoris. Circulation 1991;83:476-83.

24 Nicolela MT, Ferrier SN, Morrison CA, et al. Effects of cold-induced vasospasm in glaucoma: the role of endothelin-1. Invest Ophthalmol Vis Sci 2003;44:2565-72.

25 Buckley C, Hadoke PW, Henry E, et al. Systemic vascular endothelial cell dysfunction in normal pressure glaucoma. Br J Ophthalmol 2002;86:227-32.

26 Gass A, Flammer J, Linder L, et al. Inverse correlation between endothelin-1induced peripheral microvascular vasoconstriction and blood pressure in glaucoma patients. Graefe's Arch Clin Exp Ophthalmol 1997;235:634-8.
27 Oda $\mathrm{H}$, Murayama T, Sasaki $\mathrm{Y}$, et al. Endothelin enhances lipopolysaccharide-induced expression of inducible nitric oxide synthase in rat glial cells. Eur J Pharmacol 1997;339:253-60.

28 Marsden PA, Brenner BM. Transcriptional regulation of the endothelin-1 gene by TNF-alpha. Am J Physiol 1992;262:C854-C861.

29 Quigley HA. Neuronal death in glaucoma. Prog Retin Eye Res 1999; 18:39-57.

30 Hollander H, Makarov F, Stefani FH, et al. Evidence of constriction of optic nerve axons at the lamina cribrosa in the normotensive eye in humans and other mammals. Ophthalmic Res 1995:27:296-309.

31 Minckler DS, Bunt AH, Johanson GW. Orthograde and retrograde axoplasmic transport during acute ocular hypertension in the monkey. Invest Ophthalmol Vis Sci 1977; 16:426-41.

32 Radius RL. Optic nerve fast axonal transport abnormalities in primates. Occurrence after short posterior ciliary artery occlusion. Arch Ophthalmol 1980;98:2018-22

33 Gallant PE. The direct effects of graded axonal compression on axoplasm and fast axoplasmic transport. J Neuropathol Exp Neurol 1992;51:220-30.

34 Siesio BK. Oxygen deficiency and brain damage: localization, evolution in time, and mechanisms of damage. J Toxicol Clin Toxicol 1985;23:267-80.

35 Stokely ME, Brady ST, Yorio T. Effects of endothelin-1 on components of anterograde axonal transport in optic nerve. Invest Ophthalmol Vis Sci 2002; 43:3223-30.

36 MacCumber MW D'Anna SA. Endothelin receptor-binding subtypes in the human retina and choroid. Arch Ophthalmol 1994;112:1231-5.

37 Prasanna G, Krishnamoorthy R, Clark AF, et al. Human optic nerve head astrocytes as a target for endothelin-1. Invest Ophthalmol Vis $\mathrm{Sci}$ 2002;43:2704-13.

38 Hernandez MR. The optic nerve head in glaucoma: role of astrocytes in tissue remodeling. Prog Retin Eye Res 2000;19:297-321.

39 Yucel YH, Kalichman MW, Mizisin AP, et al. Histomorphometric analysis of optic nerve changes in experimental glaucoma. J Glaucoma 1999;8:38-45.

40 Furuyoshi N, Furuyoshi M, May CA, et al. Vascular and glial changes in the retrolaminar optic nerve in glaucomatous monkey eyes. Ophthalmologica 2000;214:24-32 